\title{
THE MULTILAYERED PLATE BEHAVIOUR UNDER BOMB IMPACT
}

\author{
Marin LUPOAE*, Ghiţă BÂRSAN**, \\ Daniel CONSTANTIN", Dan BULIGA* \\ *Military Technical Academy, Bucharest, Romania, \\ ** Land Forces Academy of Sibiu, Romania, \\ mlupoae@mta.ro,gbarsan@armyacademy.ro
}

\begin{abstract}
The paper presents some aspects regarding the response of a protective structure under the impact produced by an aerial bomb. The top slab of the protective structure is composed by three layers of different materials: rigid layer made of concrete, elastic layer made by a powdered material (clay, sand etc.) and structural layer made of concrete. The theoretical, although useful, it has not captured all the details regarding the behaviour of a layered slab under such loadings. The paper addresses in terms of numerically study the influence of different parameters of the layers (thickness, material and layout) and weapons of destruction (speed and angle of inclination of the projectile) on the maximum deformation of the base layer of the layered slab.
\end{abstract}

Keywords: multilayer slab, shelter, impact

\section{Introduction}

The world faces today with an increasingly number of risks regarding the individual and group security. These are part of both natural disasters (earthquakes, hurricanes, tornadoes, etc.) and man made events (terrorist attack, technological accidents or armed conflicts).

Therfore, it is necessary to adopt and, in particular, implement a set of adequate and consistent measure to protect the population against potential unintended consequences of extreme loading effects as a result of natural phenomena or man-made actions. Thus, it has been and will always be needed to develop military and civilian shelters to protect the personnel and facilities. Taking into account the proper behaviour under impact and explosion, the multi-layered slab has represented a ideal solution in terms of construction, being used in the postwar period for the defensive works executed in different countries around the globe.

A projectile launched on an obstacle can act on its surface, but also inside of it, beyond protecting structural elements, after it penetrated a certain depth. In the latter case, the projectile performs, until it will explode, a local damage (penetration and scabbing) in addition to a global one, as a result of the initial shock. After the detonation of the projectile explosive charge, the local damage will be extended and also the global action on the structure.

In case of an obstacle protected by a multilayer slab, the projectile could perforate the camouflage layer and reach the rigid layer, on which it would produce the effects listed above. If the projectile does not have sufficient kinetic energy to perforate the rigid layer, then, against the 
structure, it will act only the distributed pressure generated by the explosion of active charge of the projectile; the pressure will be transmitted to the base layer through the elastic layer. It follows that, unlike other structures where the effects of local and global action occur simultaneously, overlap practically, the structures having distribution layers are affected only by the global action, and its effect is obviously significantly diminished.

Considering that, it is important to establish, using numerically study, which is the best distribution of the layers (in terms of thickness, number and sequence) to obtain a minimum deflection of the base layer of the multilayer slab.

There are few papers in the litarature regarding the influence of multilayer plates on the behaviour of underground structures subjected to blast and impact. Thus, Hongyuan and Guowei [1] proposed a double-layer floor to mitigate in-structure shock of underground structures, but their proposal refers to an interior slab used to protect personnel inside and the contained devices against to the shock or severe vibration induced by the detonation. Some other papers studied aspects regarding the ground shock induced on underground structures by explosions [2]-[3] with special emphasis on the influence of the propagation medium for the shock wave. Chen et al. [4]-[5] conducted a theoretical and experimental investigation related to the dynamic response of underground structures subjected to shock and impact.

The present paper proposes a detailed numerical analysis to determine the influence of various factors (thickness of the layers, type of material for the elastic layer, number and distribution of the layers on one hand and projectile velocity and angle of impact on the other hand) on the maximum deformation of the base layer.

\section{Theoretical aspects}

In the literature, there has not been developed yet a unified theory for calculating the multilayer slab. Some references are made in [6] and [7]; first paper suggests that the multilayer slabs can be considered in terms of oscillations as a particular case of anisotropic plates and the second one presents some practical examples of calculation, based on the use of approximate methods.

A multilayer slab generally consists of: camouflage layer; rigid (protection) layer); elastic (distribution) layer and base (structural, resistance) layer. In short, the role and the embodiment of each component could be defined as follows (from the surface to the shelter):

The camouflage layer is made of vegetable earth, having a thickness strictly necessary for vegetation growth and to cover and conceal the protective structure.

The rigid layer is designed to prevent the projectile or aerial bomb to perforate and thereby to explode inside of it. For this reason, it is usually made of concrete or stone masonry, having a large thickness, which gives them a very high bending stiffness (in the calculations it is considered as infinite stiffness). In the literature this layer is called also explosion layer.

The elastic layer is designed to work with the rigid layer in order to distribute the dynamic loadings on a surface as large as possible and absorb the blast energy that propagates through the material of this layer. It is usually made by a powdered material, with or without cohesion (clay, sand, gravel, etc.). Sometimes this layer is called distribution layer. The base layer or structural layer is actually the top slab of the construction and it is made like any ordinary slab, designed for dynamic loadings.

\section{Numerical simulation}

The phenomenon of interaction between aerial bomb / projectile and layeres of a shelter, and also the interaction between shock waves resulting from the detonation of explosive charge of the warhead and layers of the protective structure is very complex and requires a thorough study to accurately determine the behavior of layer material under impact and explosion 
loadings. The conditions under which phenomena occur could greatly vary, depending on the speed of the projectile / bomb, contact angle, remaining velocity at he point of contact, number, type and thickness of layers. supported and also directely support the above two layers;

- the rigid layer and the base layer consist of a reinforced concrete, while the elastic layer is made of sand.

The action on the above mentioned configuration of layered slab is produced by

Table 1 Simulation scenarios for impact

\begin{tabular}{|c|c|c|c|c|c|c|c|}
\hline Scenario & Parameter & 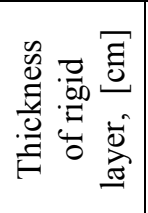 & 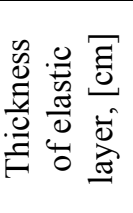 & 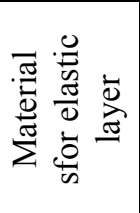 & 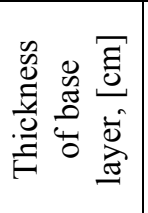 & 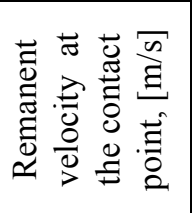 & $\begin{array}{l}\overrightarrow{0} \\
\tilde{\tilde{E}} \\
\overrightarrow{0} \\
\vec{\Xi} \\
\bar{\Xi}\end{array}$ \\
\hline S1 Influence of the & S.1.1 & 30 & 10 & sand & 30 & 200 & $25^{\circ}$ \\
\hline thickness of elastic & S.1.2 & 30 & 30 & sand & 30 & 200 & $25^{\circ}$ \\
\hline layer & S.1.3 & 30 & 50 & sand & 30 & 200 & $25^{\circ}$ \\
\hline & S.1.4 & 30 & 100 & sand & 30 & 200 & $25^{\circ}$ \\
\hline & S.1.5 & 30 & 150 & sand & 30 & 200 & $25^{\circ}$ \\
\hline S2 Influence of the & $\mathrm{S} 2.1$ & 30 & 150 & Soil & 30 & 200 & $25^{\circ}$ \\
\hline $\begin{array}{l}\text { material for elastic } \\
\text { layer }\end{array}$ & S2.2 & 30 & 150 & LECA & 30 & 200 & $25^{\circ}$ \\
\hline S3 Influence of the in & ipact angle & 30 & 150 & sand & 30 & 200 & $0^{\circ}$ \\
\hline S4 Influence of the & S4.1 $9 * 10^{3}$ & 30 & 80 & sand & 30 & 20 & $25^{\circ}$ \\
\hline initial impulse, & S4.2 $15 * 10^{3}$ & 30 & 80 & sand & 30 & 33.2 & $25^{\circ}$ \\
\hline $\mathrm{m} * \mathrm{~kg} / \mathrm{s}$ & $\mathrm{S} 4.330 * 10^{3}$ & 30 & 80 & sand & 30 & 88.5 & $25^{\circ}$ \\
\hline & S4.4 $60 * 10^{3}$ & 30 & 80 & sand & 30 & 133.5 & $25^{\circ}$ \\
\hline & S4.5 $90 * 10^{3}$ & 30 & 80 & sand & 30 & 200 & $25^{\circ}$ \\
\hline & S4.6 100*10 & 30 & 80 & sand & 30 & 230 & $25^{\circ}$ \\
\hline S5 Influence of the & S5.1 & 30 & 80 & sand & 50 & 200 & $25^{\circ}$ \\
\hline thickness of base & S5.2 & 30 & 80 & sand & 80 & 200 & $25^{\circ}$ \\
\hline layer & S5.3 & 30 & 80 & sand & 100 & 200 & $25^{\circ}$ \\
\hline
\end{tabular}

\subsection{Initial data}

To determine the influence of various parameters on the behavior of layers under dynamic loading, it was established as a potential source of dynamic actions an aviation bombs of $500 \mathrm{~kg}$. Its most important characteristics are: the total mass of $510 \mathrm{~kg}$ and the mass and type of explosive charge $-250 \mathrm{~kg}$ of TNT.

To highlight the influence of different parameters of layers on the the behavior of base layer, the following default configuration was choosen:

- all three layers has same planar dimensions $6.00 \mathrm{~m} \times 5.00 \mathrm{~m}$ and same thickness $-30 \mathrm{~cm}$;

- the base layer is boundary simply an aerial bomb of $500 \mathrm{~kg}$, at a contact angle $\alpha$ of $25^{\circ}$ and a remanent velocity at the contact point of $200 \mathrm{~m} / \mathrm{s}$.

From this initial configuration were established following scenarios impact, table 1.

\subsection{Material models}

The simulation of the impact between the bomb and layered slab was carried out using software AUTODYN / ANSYS. There were used five material models for impact modelling: Steel 1006 to model the bomb shell, TNT material model for explosive charge (for the impact the TNT material model was used as an inert charge without initiating the detonation), Concrete $35 \mathrm{MPa}$ material model for rigid and base 
layers and Sand material model for the material of distribution layer. All above mentioned material models are defined in the Autodyn library. Two new material models for soil [10] and LECA (Light Expanded Clay shale Aggregates) [11] were implemented in Autodyn in order to quantify the influence of these two types of materials of elastic layer on the maximum deflection of base layer under shock and impact. The main characteristics of materials Fig. 2 The influence of elastic layer material on the maximum deflection of the base layer used for distribution layer are presented in table 2 .

Table 2 Material characteristics for distribution layer

\begin{tabular}{|l|c|c|c|c|}
\hline Material & $\begin{array}{c}\text { fc } \\
{[\mathbf{M P a}]}\end{array}$ & $\begin{array}{c}\mathbf{E} \\
{[\mathbf{G P a}]}\end{array}$ & $\begin{array}{c}\mathbf{G} \\
{[\mathbf{M P a}]}\end{array}$ & $\begin{array}{c}\text { Density } \\
{\left[\mathbf{[ k g} / \mathbf{m}^{\mathbf{3}}\right]}\end{array}$ \\
\hline Concrete & 35 & 36 & $16.7^{*} 10^{3}$ & 2750 \\
\hline Sand & & & 76.90 & 1674 \\
\hline Soil & & & 37.64 & 1368 \\
\hline LECA & & & 27.40 & 320 \\
\hline
\end{tabular}

\subsection{Geometric model}

To achieve geometric model it was taken into account the type of solver suitable for each material models used. For simulations of the impact of the bomb on layered slab the Lagrange solver it was used. Thus all layers and bomb were modeled using Lagrangian solver. In the case of TNT explosive charge it is considered just as mass, without being required to initiate its detonation. For the bomb shape modeling it was modeled the shape as close as possible to the $500 \mathrm{~kg}$ bomb, taking into account that in the analytical model the shape parameter of the projectile does not appear as a separate parameter. Since the bomb hits the concrete plate (rigid layer) at an angle of $25^{\circ}$ (Table 1), for the 3D models it can be considered only a symmetry plan in order to model a half of the bomb and layers.

\section{Results and discussions}

\subsection{The influence of the thickness of the elastic layer}

To establish the influence of the elastic layer thickness the base layer deformation was determined using virtual gauges placed at the bottom of the base layer. The material used for elastic layer was sand with thickness of $10,30,50,100$ and $150 \mathrm{~cm}$. The maximum deformation of base layer depends on the elastic layer thickness as is shown in Fig. 1.

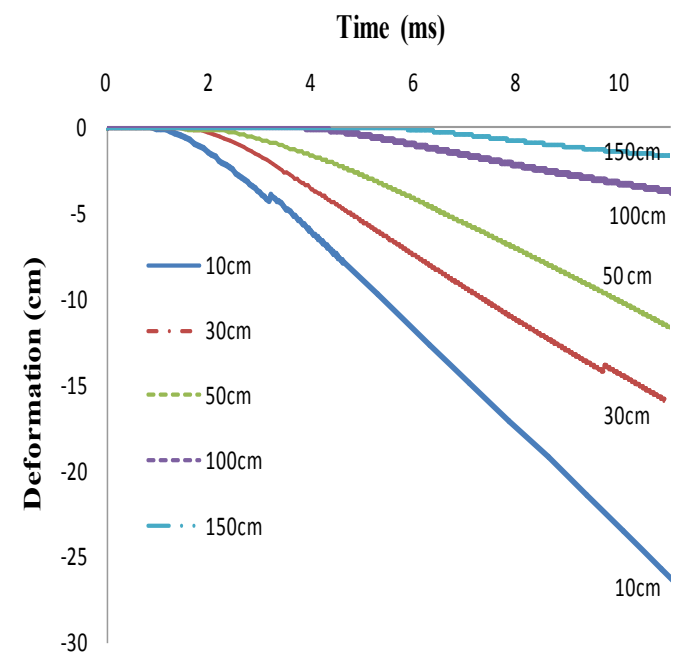

Fig. 1 The influence of the thickness of elastic layer on the maximum deflection of base layer

It results that the maximum deformation of the base layer decreases when the thickness of the sand layer increases.

\subsection{The influence of the elastic layer material}

There were tested three types of material for the elastic layer: sand, soil and LECA [11]. For each studied case it was used the same thickness of $150 \mathrm{~cm}$ for the elastic layer, the other characteristics are the same like in Table 1. The variation of maximum deformation of the base layer depending on the type of elastic layer material can be seen in Fig. 2. 


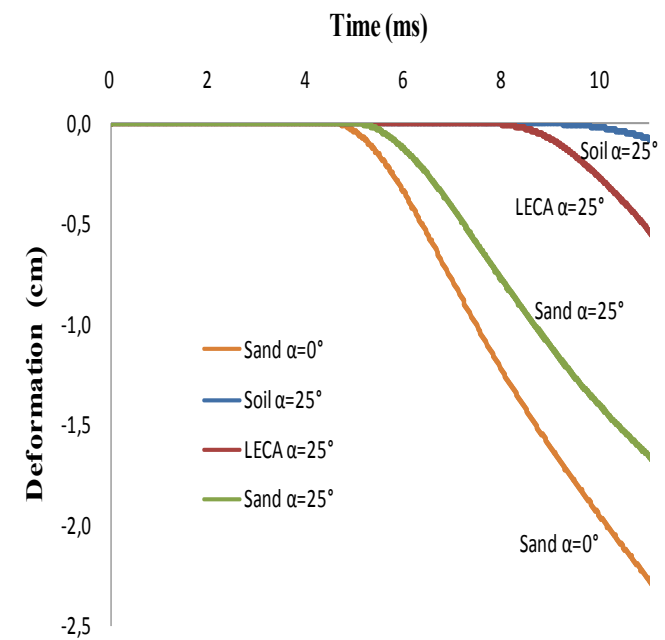

Fig. 2 The influence of elastic layer material on the maximum deflection of the base layer

It was found that the type of soil material used for simulation [10] can be a good solution to mitigate the shock produce as a result of the bomb impact, followed by the LECA and then sand.

\subsection{The influence of the angle of the bomb impact}

To study the influence of the angle of the bomb impact on the deformation of base layer, an angle of zero degrees was chosen instead of a value of $25^{\circ}$ used for all other cases. The elastic layer was made of sand and has a thickness of $150 \mathrm{~cm}$ and the other characteristics of layers and bomb are presented in Table 1. By analyzing the fig. 2 it can be seen that the effect of the bomb impact on the base layer is maximum when the impact angle of bomb is zero.

\subsection{The influence of the bomb impulse}

To determine the influence of bomb impulse at the contact point on the deformation of base layer, six different bomb velocities were used, the other characteristics of layers and bomb being presented in Table 1. The variation of maximum deformation of the base layer depending on the bomb impulse is shown in Fig. 3.

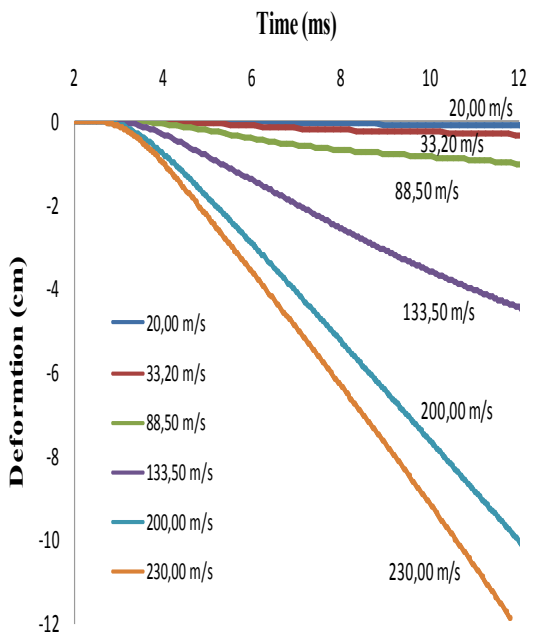

Fig. 3 The influence of the bomb impulse on maximum deformation of the base layer

It can be noticed that the maximum deformation of the base layer increases as the velocity value at the contact point increases, fig. 3. At velocities of $200 \mathrm{~m} / \mathrm{s}$ and above, the maximum deformation value of the base layer exceeds $10 \mathrm{~cm}$. The analysis of deformation of the base layers, Fig. 4 shows that at low speeds of the bomb at the point of contact appears the ricochet of the bomb due to the resistance of the concrete, a phenomenon that can not be surprised in theoretical models.

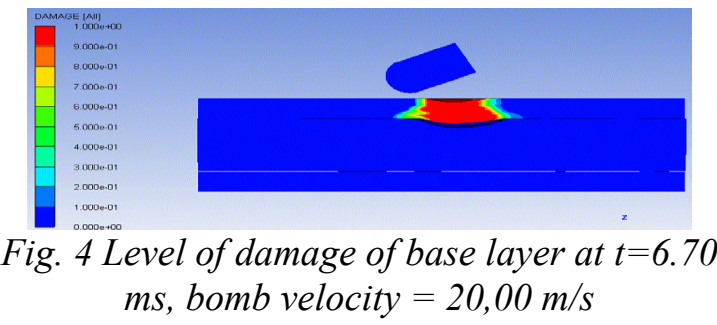

\section{Conclusions}

The simulations revealed that for the bomb characteristics taken into account (velocity at the contact point $-200 \mathrm{~m} / \mathrm{s}$ and $25^{\circ}$ impact angle) and configuration of slab with three layers of protection (rigid, elastic and base layer), the thickness of the elastic layer consisting of sand must be at least 150 $\mathrm{cm}$, so that the supporting layer does not suffer any damage.

By introducing the elastic layer material as a parameter, it was found that the best attenuation material for impact is the soil 
material (soil type prairie with $7 \%$ moisture [10]), at small difference from the sand.

Using a larger number of layers does not always bring better results in terms of deformation of the base layer. It was found that the elastic layer thickness (whose thickness can be changed with lower costs) plays an important role in reducing the deflection of the base layer. As the elastic layer thickness increases, better results are obtained when it operates alone, not distributed in several layers, even if between these layers is also added an additional rigid layer.

\section{ACKNOWLEDGMENT}

This paper has been financially supported within the project entitled "Horizon 2020 - Doctoral and Postdoctoral Studies: Promoting the National Interest through Excellence, Competitiveness and Responsibility in the Field of Romanian Fundamental and Applied Scientific Research", contract number POSDRU/159/1.5/S/140106. This project is cofinanced by the European Social Fund through Sectorial Operational Programme for Human Resources Development 2007-2013. Investing in people!

\section{References}

[1] Z. Hongyuan, M. Guowei - Double-layer floor to mitigate in-structure shock of underground structures: A conceptual design, Engineering Structures, 35, 2012, pp. 314321.

[2] Y. Lu - Underground blast induced ground shock and its modelling using artificial neural network, Computers and Geotechnics, Volume 32, Issue 3, April 2005, pp. 164 178.

[3] J.C. Li, H.B. Li, G.W. M, Y.X. Zhou - Assessment of underground tunnel stability to adjacent tunnel explosion, Tunnelling and Underground Space Technology 35, 2013, pp. 227-234.

[4] H.L. Chen , Z.C. Xia , J.N. Zhou , H.L. Fan, F.N. Jin - Dynamic responses of underground arch structures subjected to conventional blast loads: Curvature effects, Archives of Civil and Mechanical Engineering, 13, 2013, pp. 322-333.

[5] H.L. Chen, J. Zhou, H. Fan, F.Jin, Y. Xu, Y. Qiu - Dynamic responses of buried arch structure subjected to subsurface localized impulsive loading: Experimental study, International Journal of Impact Engineering 65, 2014, pp. 89-101.

[6] P. Lardy - Sur une methode nouvelle de resolution du probleme des dalles restangulaires encastrees, Publications de l'Institut de Statique Appliquée de l'Ecole Polytechnique Fédérale de Zurich Vol. 13, 1953.

[7] G. Oprea, M. Josan - Elements for multi-layered plates calculations, Military Academy Publishing House, Bucharest, 1978 (in Romanian).

[8] D. Matahală - Study of the behavior of the layered plates under dynamic loadings used for military structures, PhD Thesis, Military Technical Academy, Bucharest, 2014

[9] Comite Euro-International du Beton - Concrete structures under impact and impulsive loading, Synthesis Report, Dubrovnik, Aout 1988.

[10]D. Fiserova - Numerical analyses of buried mine explosions with emphasis on effect of soil properties on loading, $\mathrm{PhD}$ thesis, Defence College of Management and Technology, Cranfield University, England, 2006.

[11]L. Laine - Numerical Simulations Of Ground Shock Attenuation Layers For Swedish Rescu Centres And Shelters, Proceedings of the 4th Asia-Pacific Conference on Shock and Impact Loads on Structures, CI-PremierPTE LTD, Singapore, November 2001, pp. 353-360. 